\title{
To transfuse or not to transfuse? That is the question and there is more than one answer
}

\section{Editorial}

Blood is a very special juice. ${ }^{1}$ One of the first blood transfusion experiments was carried out by, and recorded in the minutes of, The Royal Society of London: "The experiment of transfusing the blood of one dog into another was made before the Society by Mr. King and Mr. Thomas Coxe, upon a little mastiff and a spaniel, with very good success, the former bleeding to death, and the latter receiving the blood of the other, and emitting so much of his own as to make him capable of receiving the other. ${ }^{2}$ "

However, it was not until a further quarter century passed, and thanks to the work of pioneers such as Geoffrey Blundell, a surgeon at Guys Hospital who carried out the first life-saving transfusion in a woman with post-partum haemorrhage, and most importantly, Karl Landsteiner who demonstrated the existence and importance of blood groups, that blood transfusion became a clinical reality. ${ }^{3,4}$

With the formation of national blood transfusion services, such as the Red Cross and similar institutions worldwide, blood transfusion rapidly became established as a vital part of a modern health service. The onset of AIDS highlighted a major problem with respect to the nosocomial spread of hitherto unexpected infections through the blood supply, and this was emphasised further by the increase in similar problems with hepatitis $C$ (then known as non-A, non-B hepatitis). Because of these infection risks, the screening of blood has become increasingly sophisticated and safe, with the risk of contracting any HIV or hepatitis $\mathrm{C}$ in the modern world being less than the risk of being hit by lightning $(<1: 1,000,000){ }^{5}$

Blood transfusion proved critically important on the battlefield, with benefits seen not only from prevention of death from acute haemorrhage, but with early surgery promoting improved wound healing and better control of sepsis; this was described graphically in a paper by Major-General Mitchiner who acknowledged that the routine use of battlefield blood transfusion was 'one of the great advances' available to combatants in the second as opposed to the first world war, and with the advice that 'as a general rule all blood lost should be replaced quantity for quantity'. ${ }^{6}$

Although replacing blood loss at surgery to maintain as nearly a normal blood count as possible seems reasonable, several studies over the past few years reveal that routine transfusion using a transfusion trigger of haemoglobin $<10 \mathrm{~g} / \mathrm{dL}$ (liberal policy) as compared to a trigger of $<7 \mathrm{~g} / \mathrm{dL}$ (restrictive policy) may have adverse effects on outcomes after surgery, trauma or in the critically unwell patient for a variety of reasons, possibly because an increase in haemoglobin with transfused blood does not necessarily lead to an increase in tissue oxygen delivery and this, together with other possibly immune-modulatory effects, leads to an increased risk of infective complications including pneumonia, mediastinitis, wound infections and sepsis. ${ }^{7}$ As a consequence, transfusion guidelines now generally recommend a restrictive transfusion policy. As a consequence, the threshold, or trigger, for making the decision to transfuse a patient, previously considered as $<10 \mathrm{~g} / \mathrm{dL}$, has now been reduced to a value of between 7 to $8 \mathrm{~g} / \mathrm{dL} .^{8-10}$
Volume 2 Issue 2 - 2016

\author{
Nick Wickham \\ Adelaide Cancer Centre, Australia
}

Correspondence: Nick Wickham, Consultant Haematologist \& Principal Investigator Clinical Haematology Trials, Australia, Email endothelium@yahoo.com

Received: January 29, 2016 | Published: February 10, 2016

This restrictive, as opposed to liberal, blood transfusion policy produces better outcomes for many hospital patients, especially postsurgical and intensive care patients. However, it has also become clear that this cannot be applied universally to all patients. A review by Mirski et al. ${ }^{11}$ in 2015 has proposed further trials for different patient groups. ${ }^{11}$ There is a spectrum, ranging from certain sub-groups who clearly do poorly with a liberal transfusion policy, such as patients with brain trauma (due to an increase in thrombotic stroke), ${ }^{12}$ to other patients where a restricted transfusion policy may not be beneficial, such as frail end elderly patients following hip fracture, who may benefit from higher haemoglobin levels to aid mobilisation. ${ }^{13}$ Other groups where a more liberal approach may be appropriate include patients with acute gastro-intestinal haemorrhage ${ }^{14}$ and those with an acute coronary syndrome, ${ }^{15}$ and concerns were raised that routine application of a restrictive transfusion policy might be premature. ${ }^{16}$

Moreover, in ambulatory patients with cancer and chemotherapyinduced anaemia, and patients with haematological disorders and anaemia due to bone marrow dysfunction such as myelodysplasia and aplasia, there is a paucity of evidence to support a particular transfusion strategy. ${ }^{17}$ Although there is evidence to show that patients with myelodysplasia requiring transfusions have a poorer quality of life and increased mortality compared to transfusion-independent patients, it is likely that this reflects the more aggressive nature of the underlying disease and other comorbidities rather than transfusion per se. ${ }^{18}$ It is also interesting that the only parameter which has demonstrated a positive correlation with quality of life is the level of haemoglobin. ${ }^{19}$ In this regard, it is somewhat ironic that a restrictive transfusion policy results in significantly lower haemoglobin than is the target haemoglobin $(12 \mathrm{~g} / \mathrm{dL})$ for patients receiving erythropoietin or transfusion to counter the anaemia associated with chemotherapy. ${ }^{19,20}$

Although there are concerns regarding the potential complications of transfusion, such as allo-immunisation, iron overload and infection, these factors may not be compelling reasons to withhold transfusion, or manage these patients with restrictive transfusion guidelines, particularly in the elderly who are sensitive to low haemoglobin levels. This is also true in the palliative care setting, where it has been shown that maintaining a higher target haemoglobin may be of benefit. ${ }^{21}$

So, Goethe's Dr Faustus was correct when he said that blood is a special juice. It is also very precious, and our current understanding of how best to make use of this resource with a more restrictive transfusion policy has undoubtedly helped hospitals and communities 
manage their blood services more efficiently and economically at a time of increasing demand. ${ }^{22}$ However, it is also clear that one size does not fit all, and that further and better studies are needed, and are underway, to determine optimal haemoglobin targets and transfusion triggers for selected groups, and in particular for those ambulatory patients who are transfusion or growth factor dependent due to bone marrow dysfunction. ${ }^{23}$ As always and as others have pointed out, we must look to provide the best possible care for our patients on an individual basis, not just treat anaemia.

\section{Acknowledgements}

None.

\section{Conflict of interest}

The author declares no conflict of interest.

\section{References}

1. Von Goethe JW. Faust (1808). Faust's Study III, I. in Faust I \& II, trans. Stuart Atkins 45; 1740

2. Minutes: Royal Society. (1666) Quoted in Nicolson MH. A record of the first blood transfusion from Pepys's Diary and the New Science 70; 1965.

3. Blundell J. A successful case of blood transfusion. Lancet 431; 1829.

4. Landsteiner K. Uber Agglutinationserscheinungen normalen menschlich Blutes. Klin Wschr. 1901;14:1132.

5. Seed CR, Kiely P, Keller AJ. Residual risk of transfusion transmitted human immunodeficiency virus, hepatitis $\mathrm{B}$ virus, hepatitis $\mathrm{C}$ virus and human T lymphotrophic virus. Inter Med J. 2005;35(10):592-598.

6. Mitchiner PH. Surgery in Two Wars. Ann $R$ Coll Surg Engl. 1947;1(2):100-111.

7. Shah A, Stanworth SJ, McKechnie S. Immunomodulatory transfusion. Evidence and triggers for the transfusion of blood and blood products. Anaesthesia. 2015;70(Suppl 1):10-19.

8. Carson JL, Grossman BJ, Kleinman S, et al. Red blood cell transfusion: a clinical practice guideline from the AABB. Ann Intern Med. 2012;157(1):49-58.

9. NICE guideline NG24. Blood Transfusion: methods, evidence and recommendations. UK: National Clinical Guideline Centre; 2015.

10. American society of anesthesiologists task force on perioperative blood management. Practice guidelines for perioperative blood management. Anesthesiology. 2015;122:241-275.
11. Mirski MA, Steven M, Frank SM, et al. Restrictive and liberal red cell transfusion strategies in adult patients: reconciling clinical data with best practice. Crit Care. 2015;19:202-212.

12. Lelubre $\mathrm{C}$, Taccone FS. Transfusion strategies in patients with traumatic brain injury: Which is the optimal hemoglobin target? Minerva Anestesiol. 2015;82(1):112-116.

13. Gregersen M, Borris LC, Damsgaard EM. Blood transfusion and overall quality of life after hip fracture in frail elderly patients-the transfusion requirements in frail elderly randomized controlled trial. J Am Med Dir Assoc. 2005;16(9):762-766.

14. Jairath V, Kahan BC, Gray A, et al. Restrictive versus liberal blood transfusion for acute upper gastrointestinal bleeding (TRIGGER): a pragmatic, open-label, cluster randomised feasibility trial. Lancet. 2015;386(9989):137-144.

15. Najafi M, Faraoni D. Hemoglobin optimization and transfusion strategies in patients undergoing cardiac surgery. World J Cardiol. 2015;7(7):377382 .

16. Nichol AD. Restrictive red blood cell transfusion strategies in critical care: does one size really fit all? Crit Care Resusc. 2008;10(4):323-327.

17. Gu Y, Estcourt LJ, Doree C, et al. Comparison of a restrictive versus liberal red cell transfusion policy for patients with myelodysplasia, aplastic anaemia, and other congenital bone marrow failure disorders. Cochrane Database Syst Rev. 2015;10:CD011577.

18. Ramsey SD, McCune JS, Blough DK, et al. Patterns of Blood Product Use among Patients with Myelodysplastic Syndrome. Vox Sang. 2012;102(4):331-337.

19. Pinchon DJ, Stanworth SJ, Doree C, et al. Quality of life and use of red cell transfusion in patients with myelodysplastic syndromes. A systematic review. Am J Hematol. 2009;84(10):671-677.

20. Borg S, Glenngard AH, Osterborg A, et al. The cost-effectiveness of treatment with erythropoietin compared to red blood cell transfusions for patients with chemotherapy induced anaemia: A Markov model. Acta Oncologica. 2008;47(6):1009-1017.

21. Tanneberger S, Melilli G, Strocchi E, et al. Use of red blood cell transfusion in palliative care services: is it still up to date or is cancerrelated anaemia controlled better with erythropoietic agents? Ann Oncol. 2004;15(5):839-844

22. Ansari S, Szallasi A. Blood management by transfusion triggers: when less is more. Blood Transfus. 2012;10:28-33.

23. Liu C, Grossman BJ. Red blood cell transfusion for hematologic disorders. Hematology Am Soc Hematol Educ Program. 2015;2015(1):454-461. 